\title{
The missing vital sign
}

The author catalogues the challenges to family, friends, and herself of managing her 10 month old son's long hospital stay as he received a transplant to cure Wiskott-Aldrich syndrome

\author{
Christina Mangurian assistant professor of clinical psychiatry, director ${ }^{1}$, Morton $\mathrm{J}$ Cowan professor \\ of paediatrics, chief $^{2}$
}

\begin{abstract}
'University of California, San Francisco, UCSF Public Psychiatry Fellowship, San Francisco General Hospital Department of Psychiatry, San Francisco, CA 94110, USA; ${ }^{2}$ University of California San Francisco, Allergy Immunology and Blood and Marrow Transplant Division, UCSF Benioff Children's Hospital, San Francisco, CA 94143, USA
\end{abstract}

This is one of a series of occasional articles by patients about their experiences that offer lessons to doctors. The $B M J$ welcomes contributions to the series. Please contact Peter Lapsley (plapsley@bmj.com) for guidance.

The paediatric bone marrow transplant team entered my 10 month old son's isolation room for a second time one morning. It was supposed to be Anderson's "day of rest" between chemotherapy and his transplant. As a physician, I knew something was wrong-busy doctors do not do rounds twice. They had returned to tell me that the umbilical cord blood needed to cure my son of his rare condition, Wiskott-Aldrich syndrome, had been thawed a day early. The doctor who had just finished his fellowship said that the early thawing would not affect Anderson. He then went on to blame the lab, saying that the "mistake probably happened because we don't really do many cord blood transplants here." The nurse practitioner told me that she thought it was likely a communication problem and promised that "this will never happen again."

At 4 months, Anderson had been diagnosed with the most severe form of Wiskott-Aldrich syndrome, a genetically inherited, immunodeficiency disease affecting 1/250 000 men. Children with severe Wiskott-Aldrich syndrome die early of infection or haemorrhage if not treated with a bone marrow transplant (BMT). Children receiving a BMT from an unrelated donor or via cord blood donation can be hospitalised for up to three months - all in an isolation room because of the risk of infection. My family had already endured a three week hospitalisation when my son was only 1 month old, and I knew that I had to develop a plan to take care of not only Anderson, but also my 4 year old daughter, my husband, and myself, physically and emotionally, during this marathon.

In stereotypical doctor fashion, I do not normally ask people to help me, nor do I prioritise taking care of myself. But facing an extremely long hospital stay with a critically ill infant and having an energetic (and thankfully healthy) 4 year old, I overcame my default tendencies. I knew the evidence that children do well, physically and emotionally, if their parents are doing well. So, my husband and I developed a plan for self care and family care based on discussions with the BMT team, families who had experienced BMTs, child psychologists, colleagues, and friends. We prioritised seeing both of our children every day, getting a good night's sleep at home at least every other night, having breaks from the hospital to spend time together, and scheduling time to exercise. We created a detailed weekly schedule and asked family, friends, and colleagues to help us with child care, laundry, and other household chores. Thanks to the "Lotsa Helping Hands" website, many of our friends and relatives signed up to have dinner delivered to our home every night, and gifts given to our floor nurses every week.

Despite all of our planning, the love showered on us by family and friends, and support from the BMT providers, nothing could prepare us for the reality of the hospitalisation. Until I began "living" on the BMT unit, I hadn't really understood what it was like to be on the other side of the patient-provider relationship. It opened my eyes to the universe of fear and vulnerability - where healthcare providers are in complete control, and patients (even those who are doctors) are at their mercy across a wide logistic and emotional divide.

The disclosure of the premature thawing of Anderson's cord blood was just one example of a missed opportunity to bridge the emotional gap. Most patients want honest discussions and the opportunity to express their feelings about bad news. Unfortunately, the initial "bad news" discussion failed on both counts. When they told me the blood was thawed early, I was petrified that Anderson had lost his chance to live. It took all of my strength not to slap both clinicians and just scream. After the team left, the physician in me needed to mobilise: I contacted the lab supervisor at a major academic medical centre 
specialising in cord blood transplantation to understand the gravity of this situation. Although this expert gave me information that reassured me, the phone call that day from our primary doctor, the chief of BMT who was on vacation at the time, really eased my worry. He apologised (using the words "I'm sorry"), took the time to explain why it was OK to do the transplant a day early, and said "Anderson will be just fine." In addition, the mother in me received the most important gift of all ... a nurse gave me the space and permission to cry.

In another example, despite the scores of publications outlining the importance of sleep, there is an unfortunate disregard for sleep in all hospitals. Getting a 10 month old to sleep can be challenging at the best of times. Add chemotherapy, pain, nausea, fevers, and vital sign checks every four hours - and the sleep routine becomes extraordinarily complex. With additional interruptions-such as second year residents "eyeballing" the child at $9 \mathrm{pm}$, noisy intravenous line changes at $10 \mathrm{pm}$, or a dermatology fellow conducting a late night exam and biopsy - the situation becomes a nightmare. I understand there are excellent clinical reasons for these interruptions-especially for critically ill children — but hospitals must start paying more attention to protecting the sleep of their patients and their carers, which could improve clinical outcomes and reduce emotional stress.

Feeling absolutely no control over this life and death situation, my husband and I struggled constantly with emotions such as vulnerability, fear, and anger. As a psychiatrist, I knew these feelings were normal, but there was no mental health professional on the BMT team assigned to help us. Social workers were available, but they seemed to deal with the "problem cases," not the "easier" ones such as ours. Child life specialists made my son's daytime life "normal," but they did not attend to my emotions. Thankfully, I had my own psychiatrist, my husband, my parents, and friends to turn to for the emotional support I needed. Many families are not so fortunate.

It struck me again and again that, because of the increasing complexity of medical care, doctors do not seem to have the time to take the "emotional temperature" of patients or their carers during prolonged hospitalisations, nor are providers thinking critically about essential, patient centred concerns to facilitate wellness. In my opinion, we were treated at the best paediatric BMT unit in the country, but the empathic failures made me wonder about the emotional experience for families at other hospitals.
I believe that doctors who are treating children for prolonged periods should ask the parents how they are feeling about being in the hospital every day. If this is unreasonable given time constraints, then add a team member to fill this role. Again, there is plenty of evidence that children do better if their parents are emotionally grounded. By not being asked, parents may have the impression that the doctors don't care, and clinicians may miss important warning signs of parental depression or anxiety that could negatively affect outcomes for critically ill children.

About a week after the transplant, the chief of paediatric BMT visited us on the day he returned from vacation. By that point, it was clear that the cord blood cells had been in optimal condition, so the mistake did not seem to have ramifications. That said, it was obviously still on our minds. Without ceremony, his first words to me were, "Hi, Mom, how are you doing? Do you need a hug?" As a psychiatrist, I was taught not to hug my patients, but at that moment I did need a hug, and I needed it from him. I needed it from my son's doctor, the person we were counting on to save his life, the person who was supposed to help us through this terrible ordeal. Although his bedside manner is not generally "touchy-feely," our doctor knew that I needed him to cross the doctor-patient-parent boundary. His small gesture took no extra "resources" and little extra time. Yet, it instantly made me feel better; and is ultimately what makes him not just good, but a great doctor.

$\mathrm{CM}$ has a Career Development Award from the National Institute of Mental Health (K23MH093689). The content is solely the responsibility of the authors and does not necessarily represent the official views of the National Institutes of Health.

Competing interests: We have read and understood the BMJ Group policy on declaration of interests and have no relevant interests to declare.

Provenance and peer review: Not commissioned; not externally peer reviewed.

Patient consent: Not required; the corresponding author is the (infant) patient's mother.

Accepted: 30 March 2013

Cite this as: BMJ 2013;346:f4163

(c) BMJ Publishing Group Ltd 2013 


\section{A clinical perspective}

As a physician who has cared for children receiving bone marrow transplants (BMTs) at a major academic medical centre for over 30 years, I know full well that a BMT hospitalisation is among the most challenging experiences a family will ever go through. On top of that, for most patients (and parents) the disease for which the transplant is being done is life threatening and usually incurable without a transplant. Also, it is among the most challenging medical procedures in the hospital, requiring a large medical team to pay meticulous attention over a relatively long period of time to numerous details that affect patient outcomes. The social issues that our teams must consider are also complex, including parents who are frightened and depressed, living far from home and support systems, being separated from each other and their other children, and dealing with financial stresses over costs for food and travel not covered by third party payers, potential job loss, etc.

Anderson's mother highlights the critical need for psychological and social support for all patients and their families who are hospitalised, especially those undergoing complex, life threatening, and lengthy care. Can we do better in terms of psychosocial support? The answer is clearly yes, but we also need to design improved ways of using the resources that we already have to optimise this aspect of care. The problem is how do we do this?

Although intuitively, providing this psychological support makes perfect sense, there are limited studies to guide us as to who on the team should be providing this support for carers. At most centres, it is up to the team as a whole to work together for the mental health of the carer and patient. Not every healthcare professional has the ability or expertise (or experience) to provide the support that's needed. While some centres rely on psychologists to provide this support, most rely on social workers to identify psychosocial issues and work with the team to resolve them. Nurses, who often spend hours with a patient as part of the team, can also provide important support. In addition, there is no question that some patients and families require more support than others. Since the individual needs vary, there may not be one person who can satisfy the psychological needs of every patient or parent.

Since everyone is involved in the care, I believe that the psychosocial status should be on the patient's "problem list" and addressed every day. In addition, someone should be "checking in" with the family at least once or twice a week, or daily if necessary. Weekly psychosocia rounds to address particular problems can also be held to help focus on the needs of carers. Parent support groups may also help. The most important goal with respect to psychosocial care is to attempt to identify and deal with problems before they become crises. What is desperately needed in this area are well defined studies and controlled interventions to identify the most optimal and cost effective approaches for all of our patients.

Morton J Cowan

\section{Useful resources for health professionals, patients, and carers}

Be The Match: National Marrow Donor Program (www.marrow.org)_-"For people with life-threatening blood cancers like leukaemia and lymphoma or other diseases, a cure exists. Be The Match connects patients with their donor match for a life-saving marrow or umbilical cord blood transplant"

Carers UK (www.carersuk.org) - A charity set up to help people who care for family or friends. It provides information and advice about caring, plus practical and emotional support for carers

Caring Bridge (www.caringbridge.org)-Has personal, protected sites that make it easy to stay connected during any type of health event. Family and friends can visit the site to stay informed and leave supportive messages. They also have a SupportPlanner calendar that helps family and friends coordinate care and organise helpful tasks such as providing meals, offering rides, and taking care of pets Care Pages (https://www.carepages.com)—Websites are free patient blogs that connect friends and family during a health challenge Family Fund (www.familyfund.org.uk) - "The UK's largest provider of grants to low income families raising disabled and seriously ill children and young people. ... We can help with essential items such as washing machines, fridges and clothing but can also consider grants for sensory toys, computers and much needed family breaks together"

Immune Deficiency Foundation (www.primaryimmune.org)—Provides information and support for patients with a primary immunodeficiency disease. It also provides information for healthcare professionals

Lotsa Helping Hands (www.lotsahelpinghands.com)_-Connects people through the power of community-whether you need help or you want to provide help. You may be caring for an ill loved one, an aging parent, a child with special needs or a veteran. You may want to volunteer to help a friend or others in your neighbourhood"

Rainbow Trust Children's Charity (www.rainbowtrust.org.uk)—Provides emotional and practical support to families who have a child with a life threatening or terminal illness

WAS Community (www.wiskott.org)-Community resource portal created by the Wiskott-Aldrich Foundation for patients and their families. It includes practical information about the disorder and links to support groups and other resources 